\title{
Association between Insomnia and Subclinical Atherosclerosis Among Chinese Steelworkers: A Cross-sectional Survey
}

\section{Lihua Wang ( $\square$ wanglihua@stu.ncst.edu.cn )}

North China University of Science and Technology https://orcid.org/0000-0002-8109-3362

Shengkui Zhang

North China University of Science and Technology

Miao Yu

North China University of Science and Technology

Juxiang Yuan

North China University of Science and Technology

\section{Research}

Keywords: Insomnia, Carotid plaque, Subclinical atherosclerosis, Steelworker

Posted Date: December 28th, 2021

DOI: https://doi.org/10.21203/rs.3.rs-1124233/v1

License: (a) (i) This work is licensed under a Creative Commons Attribution 4.0 International License.

Read Full License

Version of Record: A version of this preprint was published at Archives of Public Health on March 14th, 2022. See the published version at https://doi.org/10.1186/s13690-022-00834-1. 


\section{Abstract}

Background: Insomnia is a common prevalent sleep disorder. Difficulty maintaining sleep or poor in quality in insomnia caused by disrupted or misaligned circadian rhythms may play an important role in the development of atherosclerosis. This study aimed to examine the association between insomnia and subclinical atherosclerosis in Chinese steelworkers.

Methods: A total of 3582 subjects from a large enterprise located in northern China were included in this study. The Athens Insomnia Scale (AIS) was used to assess the status of insomnia. Subclinical atherosclerosis was evaluated using ultrasonographic measurements of carotid plaque. Multivariable logistic regression was used to identify association between insomnia and carotid atherosclerosis.

Results: The overall prevalence of insomnia and carotid plaque were $35.1 \%$ and $29.9 \%$ in the study population. Compared with non-insomnia workers, significantly increased odds of carotid plaque were observed among insomnia workers after adjustment for potential confounders, odds ratio $(O R)=1.38$, 95\% confidence interval (Cl): 1.17 to 1.62 . Exposure to current shift work and insomnia simultaneously can significantly elevated odds of carotid plaque. No significant association was found in female workers between insomnia and carotid plaque.

Conclusion: Insomnia is associated with elevated odds of carotid atherosclerosis in male steelworkers. Insomnia problems of workers should receive further attention in occupational worker health interventions.

\section{Background}

Insomnia is a common prevalent sleep disorder characterized by difficulty initiating or maintaining sleep, accompanied by symptoms such as irritability or fatigue during wakefulness [1]. The prevalence of insomnia varies from $6-48 \%$ in more than 50 epidemiological studies according to different definitions [2], suggesting that individuals with insomnia constitute a considerable proportion and insomnia has become one of the most common and widely recognized public health problems on a global scale [3]. Insomnia is a risk factor for the emergence and development of numerous somatic and mental disorders [4] and follows a chronic course in $40-70 \%$ of individuals over 1-20 years [1]. Functional consequences of insomnia including reduced productivity, increased absenteeism, and increased health care costs and a declined quality of working life [5-7].

Cardiovascular diseases (CVD) continue to be the leading cause of death and the largest contributor to premature mortality worldwide [8], being the cause of $40 \%$ of deaths in the Chinese population [9]. However, CVD develops over a long period with physical changes beginning decades before the disease manifests itself. Therefore, it is important to include surrogate parameters that describe early subclinical changes [10]. The measure of subclinical atherosclerosis in several body locations, such as carotid, femoral and coronary arteries, allows one to find evidence of vascular disease before it causes symptoms [11]. Ultrasound examination of the carotid arteries is an easily accessible tool by which one can identify 
early subclinical atherosclerosis by the detection of plaques. In concrete, the presence of carotid plaques has been shown to improve significantly the better [12] risk prediction of major cardiovascular events [13-15], and the accuracy for the diagnosis of coronary artery disease [16].

A substantial percentage of shift workers often experience reduced sleep quality, duration and/or excessive sleepiness due to the imposed conflict between work and their circadian system [17]. It is estimated that about $32 \%$ of night workers, $10 \%$ of day workers [18], and $8-26 \%$ of rotating shift workers $[19,20]$ suffer from shift work disorder (SWD), a circadian rhythm sleep disorder characterized by insomnia and/or excessive sleepiness as a result of chronic mismatch between shift workers' sleep-wake schedule and circadian clock [21]. Difficulty maintaining sleep, or sleep that is chronically nonrestorative or poor in quality in insomnia caused by disrupted or misaligned circadian rhythms may play an important role in the autonomic nervous system and chronic inflammatory during sleep, resulting in the development of atherosclerosis [22, 23]. However, the results of several studies on insomnia and subclinical atherosclerosis were inconsistent $[22,24]$ and data from population-based studies sparse. The aim of our study was to examine the relation between insomnia and carotid plaque in the steelworkers.

\section{Methods}

\section{Study design and population}

This study was based on a cross-sectional data from the occupational population, which conducted among steelworkers at 11 steel production departments owned by the HBIS Group's Tangsteel Company in Tangshan City, Hebei Province in north China. All workers at this company underwent a legally required health examination each year. A total of 7661 participants who underwent the annual required legally occupational health examinations were recruited from February to June 2017. There were 4084 workers who volunteered and completed carotid ultrasound examinations. After excluding 97 workers without complete items in the insomnia scale; 205 workers without sufficient shift work data, 200 workers without complete information on main covariates on the questionnaire, a total of 3582 participants were included for the final analysis. All participants gave informed consent before taking part in this study. The research was approved by the Ethics Committee of North China University of Science and Technology (No.16040).

\section{Assessment of insomnia}

The entire 8-item Athens Insomnia Scale (AIS) based on the International Classification of Diseases, Tenth Revision (ICD-10) diagnostic criteria of insomnia was employed as the insomnia assessment tool in this study [25]. The first 5 items evaluate difficulty with sleep induction, awakening during the night, early-morning awakening, total sleep time, and overall quality of sleep; the last 3 items focus on sense of well-being, overall functioning, and sleepiness during daytime. Each item was scored on a 4-point Likert scale from 0 (no problem at all) to 3 (a very serious problem), with the total score ranging from 0 to 24 . $A$ 
score of $\geq 6$, which being the widely accepted cut-off value for insomnia, classified the workers into the insomnia group; other workers were classified as the non-insomnia group.

\section{Measurement of plaque in the carotid artery}

Assessment of plaque from both left and right carotid artery systems was performed using a highresolution B-mode topographic ultrasound system (PHILIPS, HD7, China) by two trained sonographers who were blinded to the research purpose and the study design. Participants were examined in the supine position with their head rotated in the opposite direction to the probe and with a lateral probe orientation. For this study, atherosclerotic plaques were defined as focal structures encroaching into the arterial lumen of at least $0.5 \mathrm{~mm}$ or $50 \%$ of the surrounding IMT value, or demonstrates a thickness $>1.5 \mathrm{~mm}$ as measured from the intima-lumen interface to the media-adventitia interface [26]. When a local protrusion was defined as a plaque, its maximum thickness $(\mathrm{mm})$ was measured using ultrasound calipers [27]. The carotid plaque score indicates the severity of atherosclerosis, which is the sum of the cumulative maximum thickness of plaques obtained in the longitudinal sections of the common carotid artery, bifurcation, and internal carotid artery of the left and right carotid systems [28].

\section{Assessment of covariates}

Information on demographic characteristics, work lifestyle behavior, clinical characteristics were collected via face-to-face questionnaire survey, physical and biochemical examination. The duration of sleep was the weighted averages of sleep on working days and rest days, and divided into two groups according to 6 hours. Habitual snoring was defined as a self-report of snoring $>4$ times per week. Workers were asked if they had taken any sleeping pills in the past month. Smoking status was divided into "never", "ever" and "current". Those who regularly consumed $\geq 1$ cigarette/day over the past 12 months were defined as current smokers. Drinking status was divided into "never", "ever" and "current". Those who usually consumed some alcohol at least once a week over the past 12 months were defined as current drinkers. Considering that current lifestyle habits have a more significant effect on insomnia, and the proportion of past smokers, past drinkers and former shift workers were smaller, we divided these three variables into two categories according to "current" state. Dietary patterns were assessed based on the DASH (dietary approaches to stop hypertension, DASH) diet score [29]. The calculation of metabolic equivalents was based on the International Physical Activity Questionnaire (IPAQ) [30]. The workers with metabolic equivalent task (MET) [min/week] values $<600,600-3000$ and $>3000$ were classified as having a low, moderate, and high level of physical activity respectively. Body mass index (BMI) was defined as body weight $(\mathrm{kg})$ divided by the square of the body height $\left(\mathrm{m}^{2}\right)$. The main work schedule of the present study population has been introduced in detail in our previous research [31]. Shift status was classified as never/ever and current in this study. Hypertension was defined as current systolic blood pressure $\geq$ $140 \mathrm{mmHg}$, or diastolic blood pressure $\geq 90 \mathrm{mmHg}$, or if the patient was receiving antihypertensive therapy. Diabetes was defined as fasting blood glucose $\geq 7.0 \mathrm{mmol} / \mathrm{L}$ or if the patient was receiving 
hypoglycemic therapy. Total cholesterol (TC) $\geq 6.22 \mathrm{mmol} / \mathrm{L}$ or low-density lipoprotein (LDL-C) $\geq 4.11$ $\mathrm{mmol} / \mathrm{L}$ or high-density lipoprotein $(\mathrm{HDL}-\mathrm{C}) \leq 1.04 \mathrm{mmol} / \mathrm{L}$ or triglycerides $(\mathrm{TG}) \geq 2.32 \mathrm{mmol} / \mathrm{L}$, or patients undergoing lipid-lowering therapy were considered to demonstrate dyslipidemia.

\section{Statistical analysis}

Continuous variables are presented as means and standard deviations, and between-group comparisons were performed using Student's t-test or analysis of variance (ANOVA) if the data were normally distributed. Otherwise, the median (upper quartile-lower quartile) and Wilcoxon rank sum test were used to describe and compare these continuous variables between groups. Categorical variables are presented as numbers and percentages, and the chi-square test was used to compare differences among groups. Associations between insomnia and carotid plaque were reported as odds ratios (OR) and corresponding 95\% confidence intervals from multivariable adjusted logistic regression models. The risk factors and potential confounders were included in the analysis. We fit an age-adjusted model (model 1) and a multivariable (model 2) model additionally including sex and a final multivariable model (model 3) additionally adjusted for other confounders and known risk factors: marital status, educational level, BMI (categorical), smoking, drinking, DASH score, physical activity, shift work, sleep duration (categorical), sleep drug, snore, hypertension, diabetes, dyslipidemia. Subsequently, in subgroup analysis, we introduced multiplicative interaction terms using the insomnia and the stratifying factors including sex, BMI ( $<25 \mathrm{~kg} / \mathrm{m}^{2}$ or $\geq 25 \mathrm{~kg} / \mathrm{m}^{2}$ ), smoking status (no/current), drinking status (no/current), snore (no/yes), shift work (no/current), sleep duration (< 6 hours or $\geq 6$ hours), diabetes (no/yes), hypertension (no/yes), and dyslipidemia (no/yes) to assess potential effects modification. Log likelihood ratio test was used to compare models with and without cross-product interaction terms. A two-tailed $p<0.05$ was considered statistically significant. All statistical analyses were performed using SAS V.9.4.

\section{Results}

\section{General characteristics of the participants}

Table 1 shows the general characteristics of the study participants according to the insomnia status. The present study of 3582 included participants consisted of $90.5 \%$ males, with a mean age of 46.0 years, and a mean sleep duration of 6.8 hours. The prevalence of hypertension, diabetes and dyslipidemia in study participants were $32.3 \%, 13.6 \%$, and $40.1 \%$, respectively. Among workers included, the prevalence of insomnia was $35.1 \%$, and the proportion of current shift workers was $59.1 \%$. Presence of plaque, diabetes, snore, sleep drug and current shift were more likely to be reported among current insomnia workers. Compared with non-insomnia workers, the sleep duration was relatively short and the DASH score was relatively low among insomnia workers. In terms of current health status, insomnia workers also showed higher levels of systolic blood pressure and diastolic blood pressure. Workers with carotid plaque were more likely to be current shift workers, male, current smokers, current drinkers, and those with hypertension, diabetes or dyslipidemia (Table S1). As shown in Table S2, the prevalence rates of carotid 
plaque in male and female were $31.7 \%$ and $12.3 \%$, respectively. Compared with female workers, male workers had higher levels of BMI, blood pressure and plaque score, and higher proportions of smoking, drinking, snore, current shift, hypertension, diabetes and dyslipidemia (Table S2). 
Table 1

Basic characteristics of participants according to insomnia

\begin{tabular}{|c|c|c|c|c|}
\hline \multirow[t]{2}{*}{ Variables } & Total & Non-insomnia & Insomnia & \multirow{2}{*}{ Value } \\
\hline & $\mathrm{N}=3582$ & $n=2324$ & $n=1258$ & \\
\hline Plaque, n (\%) & $1070(29.9)$ & $644(27.7)$ & $426(33.9)$ & $<0.001$ \\
\hline Plaque score (mm), median (IQR) & $2.7(1.8,4.8)$ & $3.1(1.8,5.2)$ & $2.3(1.6,4.0)$ & $<0.001$ \\
\hline Age (years), mean (SD) & $46.0(7.9)$ & $45.9(8.0)$ & $46.1(7.6)$ & 0.456 \\
\hline Sleep duration (h), mean (SD) & $6.8(1.2)$ & $6.8(1.1)$ & $6.6(1.3)$ & $<0.001$ \\
\hline DASH score, mean (SD) & $21.6(2.4)$ & $21.7(2.4)$ & $21.4(2.3)$ & 0.003 \\
\hline $\begin{array}{l}\text { Physical activity (MET-h/week), } \\
\text { median (IQR) }\end{array}$ & $\begin{array}{l}113.0(78.6 \\
153.3)\end{array}$ & $\begin{array}{l}109.5(77.4 \\
153.3)\end{array}$ & $\begin{array}{l}119.6(82.5 \\
163.8)\end{array}$ & $<0.001$ \\
\hline BMI $\left(\mathrm{kg} / \mathrm{m}^{2}\right)$, mean (SD) & $25.2(3.3)$ & $25.2(3.3)$ & $25.2(3.4)$ & 0.694 \\
\hline $\begin{array}{l}\text { Systolic blood pressure (mmHg), } \\
\text { mean (SD) }\end{array}$ & $129.5(16.6)$ & $129.1(16.3)$ & $130.3(17.0)$ & 0.027 \\
\hline $\begin{array}{l}\text { Diastolic blood pressure }(\mathrm{mmHg}) \\
\text { mean (SD) }\end{array}$ & $82.8(10.7)$ & $82.5(10.5)$ & $83.3(10.9)$ & 0.033 \\
\hline $\begin{array}{l}\text { Fasting blood glucose (mmol/L), } \\
\text { mean (SD) }\end{array}$ & $6.1(1.4)$ & $6.1(1.4)$ & $6.1(1.4)$ & 0.583 \\
\hline $\begin{array}{l}\text { Total cholesterol }(\mathrm{mmol} / \mathrm{L}) \text {, mean } \\
\text { (SD) }\end{array}$ & $5.1(1.0)$ & $5.1(1.0)$ & $5.2(1.0)$ & 0.105 \\
\hline Triglycerides (mmol/L), mean (SD) & $1.7(1.5)$ & $1.7(1.5)$ & $1.7(1.6)$ & 0.605 \\
\hline $\mathrm{HDL}-\mathrm{C}(\mathrm{mmol} / \mathrm{L})$, mean (SD) & $1.3(0.3)$ & $1.3(0.3)$ & $1.3(0.3)$ & 0.200 \\
\hline LDL-C (mmol/L), mean (SD) & $3.3(0.9)$ & $3.2(0.9)$ & $3.3(0.9)$ & 0.089 \\
\hline Age (years), n (\%) & & & & 0.298 \\
\hline $23-29$ & $158(4.4)$ & $108(4.7)$ & $50(4.0)$ & \\
\hline $30-39$ & $594(16.6)$ & $397(17.1)$ & $197(15.7)$ & \\
\hline $40-49$ & $1464(40.9)$ & 926 (39.9) & $538(42.8)$ & \\
\hline $50-60$ & $1366(38.1)$ & $893(38.4)$ & $473(37.6)$ & \\
\hline
\end{tabular}

Values are expressed as the mean (SD) or median (IQR) or number (\%); p values were from Pearson's $\chi 2$ test for categorical variables and Student's t-test or Wilcoxon rank sum test for continuous variables. DASH, dietary approaches to stop hypertension; MET, metabolic equivalent of task; BMI, body mass index; HDL-C, high density lipoprotein cholesterol; LDL-C, low density lipoprotein cholesterol. 


\begin{tabular}{|c|c|c|c|c|}
\hline \multirow[t]{2}{*}{ Variables } & Total & Non-insomnia & Insomnia & \multirow{2}{*}{$\stackrel{p}{\text { Value }}$} \\
\hline & $N=3582$ & $n=2324$ & $n=1258$ & \\
\hline Education level, n (\%) & & & & 0.851 \\
\hline Primary or Middle & $1049(29.3)$ & $674(29.0)$ & $375(29.8)$ & \\
\hline High school or college & $1900(53.0)$ & $1235(53.1)$ & $665(52.9)$ & \\
\hline University and above & $633(17.7)$ & $415(17.9)$ & $218(17.3)$ & \\
\hline Marital status, n (\%) & & & & 0.498 \\
\hline Unmarried & $104(2.9)$ & $69(3.0)$ & $35(2.8)$ & \\
\hline Married & $3382(94.4)$ & $2198(94.6)$ & $1184(94.1)$ & \\
\hline Other & $96(2.7)$ & $57(2.5)$ & $39(3.1)$ & \\
\hline Smoking status, n (\%) & & & & 0.723 \\
\hline Never/Ever & $1720(48.0)$ & $1121(48.2)$ & $599(47.6)$ & \\
\hline Current & $1862(52.0)$ & $1203(51.8)$ & $659(52.4)$ & \\
\hline Drinking status, n (\%) & & & & 0.070 \\
\hline Never/Ever & $2210(61.7)$ & $1459(62.8)$ & $751(59.7)$ & \\
\hline Current & $1372(38.3)$ & $865(37.2)$ & $507(40.3)$ & \\
\hline DASH score, n (\%) & & & & 0.003 \\
\hline$<20$ & $593(16.6)$ & $358(15.4)$ & $235(18.7)$ & \\
\hline $20-21$ & $1171(32.7)$ & 736 (31.7) & $435(34.6)$ & \\
\hline $22-23$ & $1139(31.8)$ & 767 (33.0) & $372(29.6)$ & \\
\hline$\geq 24$ & $679(19.0)$ & $463(19.9)$ & $216(17.2)$ & \\
\hline Physical activity, n (\%) & & & & 0.217 \\
\hline Low & $37(1.0)$ & $29(1.3)$ & $8(0.6)$ & \\
\hline Moderate & $252(7.0)$ & $165(7.1)$ & 87 (6.9) & \\
\hline High & 3293 (91.9) & 2130 (91.6) & 1163 (92.4) & \\
\hline
\end{tabular}

Values are expressed as the mean (SD) or median (IQR) or number (\%); $p$ values were from Pearson's $\chi 2$ test for categorical variables and Student's t-test or Wilcoxon rank sum test for continuous variables. DASH, dietary approaches to stop hypertension; MET, metabolic equivalent of task; BMI, body mass index; HDL-C, high density lipoprotein cholesterol; LDL-C, low density lipoprotein cholesterol. 


\begin{tabular}{|c|c|c|c|c|}
\hline \multirow[t]{2}{*}{ Variables } & Total & Non-insomnia & Insomnia & \multirow{2}{*}{$\begin{array}{l}p- \\
\text { Value }\end{array}$} \\
\hline & $N=3582$ & $\mathrm{n}=2324$ & $\mathrm{n}=1258$ & \\
\hline \multicolumn{3}{|l|}{ BMI $\left(\mathrm{kg} / \mathrm{m}^{2}\right), \mathrm{n}(\%)$} & & 0.834 \\
\hline$<25$ & $1797(50.2)$ & $1164(50.1)$ & $633(50.3)$ & \\
\hline $25-30$ & $1506(42.0)$ & $983(42.3)$ & $523(41.6)$ & \\
\hline$\geq 30$ & $279(7.8)$ & $177(7.6)$ & $102(8.1)$ & \\
\hline \multicolumn{3}{|l|}{ Hypertension, n (\%) } & & 0.099 \\
\hline No & $2426(67.7)$ & $1596(68.7)$ & $830(66.0)$ & \\
\hline Yes & $1156(32.3)$ & $728(31.3)$ & $428(34.0)$ & \\
\hline \multicolumn{4}{|l|}{ Diabetes, n (\%) } & 0.040 \\
\hline No & 3098 (86.5) & $2030(87.4)$ & $1068(84.9)$ & \\
\hline Yes & $484(13.5)$ & $294(12.7)$ & $190(15.1)$ & \\
\hline \multicolumn{4}{|l|}{ Dyslipidemia, n (\%) } & 0.735 \\
\hline No & $2149(60.0)$ & $1399(60.2)$ & $750(59.6)$ & \\
\hline Yes & $1433(40.0)$ & $925(39.8)$ & $508(40.4)$ & \\
\hline \multicolumn{4}{|l|}{ Snore, n (\%) } & 0.003 \\
\hline No & $1868(52.2)$ & $1254(54.0)$ & $614(48.8)$ & \\
\hline Yes & $1714(47.8)$ & $1070(46.0)$ & $644(51.2)$ & \\
\hline \multicolumn{4}{|l|}{ Sleep drug, n (\%) } & $<0.001$ \\
\hline No & 3408 (95.1) & $2247(96.7)$ & $1161(92.3)$ & \\
\hline Yes & $174(4.9)$ & 77 (3.3) & $97(7.7)$ & \\
\hline \multicolumn{4}{|l|}{ Shift work, n (\%) } & 0.027 \\
\hline Never/Ever & $1464(40.9)$ & $981(42.2)$ & $483(38.4)$ & \\
\hline Current & $2118(59.1)$ & $1343(57.8)$ & $775(61.6)$ & \\
\hline \multicolumn{4}{|l|}{ Sleep duration (hour), n (\%) } & $<0.001$ \\
\hline \multicolumn{5}{|c|}{$\begin{array}{l}\text { Values are expressed as the mean (SD) or median (IQR) or number (\%); p values were from Pearson's } \\
\chi 2 \text { test for categorical variables and Student's t-test or Wilcoxon rank sum test for continuous } \\
\text { variables. DASH, dietary approaches to stop hypertension; MET, metabolic equivalent of task; BMI, } \\
\text { body mass index; HDL-C, high density lipoprotein cholesterol; LDL-C, low density lipoprotein } \\
\text { cholesterol. }\end{array}$} \\
\hline
\end{tabular}




\begin{tabular}{|c|c|c|c|}
\hline \multirow[t]{2}{*}{ Variables } & Total & Non-insomnia & Insomnia \\
\hline & $N=3582$ & $n=2324$ & $n=1258$ \\
\hline$<6$ & $444(12.4)$ & $209(9.0)$ & 235 (18.7) \\
\hline$\geq 6$ & 3138 (87.6) & 2115 (91.0) & $1023(81.3)$ \\
\hline \multicolumn{4}{|c|}{$\begin{array}{l}\text { Values are expressed as the mean (SD) or median (IQR) or number (\%); } p \text { values were from Pearson's } \\
\text { X } 2 \text { test for categorical variables and Student's t-test or Wilcoxon rank sum test for continuous } \\
\text { variables. DASH, dietary approaches to stop hypertension; MET, metabolic equivalent of task; BMI, } \\
\text { body mass index; HDL-C, high density lipoprotein cholesterol; LDL-C, low density lipoprotein } \\
\text { cholesterol. }\end{array}$} \\
\hline
\end{tabular}

\section{Association Between Insomnia And Carotid Plaque}

The prevalence of carotid plaque was $29.9 \%$ overall in this study population (Table 1 ). Table 2 shows results from the logistic regression model. Compared with non-insomnia workers, significantly increased odds ratios (OR) of carotid plaque were observed in insomnia workers after adjustment for age and sex ( $\mathrm{OR}=1.36,95 \% \mathrm{Cl}: 1.16$ to 1.59 ). After additionally adjusting for marital status, educational level, $\mathrm{BMI}$, smoking, drinking, DASH score, physical activity, current shift, sleep duration, snore, sleep drug, diabetes, hypertension, and dyslipidemia, this association remained robust ( $\mathrm{OR}=1.38,95 \% \mathrm{Cl}$ : 1.17 to 1.62 ) (Table 3). No significant associations were observed among female workers ( $\mathrm{OR}=1.78,95 \% \mathrm{Cl}$ : 0.84 to 3.76 ) (Table 4). Cross-classification analyses showed that exposure to current shift work and insomnia simultaneously can significantly elevated odds of carotid plaque $(\mathrm{OR}=2.34,95 \% \mathrm{Cl}: 1.82$ to 2.99 , in sleep duration $\geq 6$ hours group; $\mathrm{OR}=1.59,95 \% \mathrm{Cl}$ : 1.08 to 2.36 , in sleep duration $<6$ hours group), compared with never/ever shift work, non-insomnia and sleep duration $\geq 6$ hours workers (Table 3 ). We analyzed the relationship between insomnia and carotid plaque through stratification analysis based on potential effect modifiers (Table 4). Compared with non-insomnia workers, elevated odds of carotid plaque were observed in insomnia workers in almost all subgroup analyses. There was no significant effect modification of the association between insomnia and carotid plaque by sex, smoking status, drinking status, BMI, DASH score, hypertension, diabetes and dyslipidemia (all $p$ for interaction $>0.05$ ). Considering that dust, heat stress, noise, and carbon monoxide (see supplementary appendix) are the main occupational hazards to the current steelworkers, we further adjusted these exposures on the basis of Model 3 in Table 2, and the results remained robust (Table S3). 
Table 2

Multivariate adjusted ORs between carotid plaque and insomnia

\begin{tabular}{|c|c|c|c|c|}
\hline \multirow[t]{2}{*}{ Insomnia } & \multirow[t]{2}{*}{ Total, $\mathbf{n}(\%)$} & \multicolumn{3}{|l|}{ OR (95\% Cl) } \\
\hline & & Model 1 & Model 2 & Model 3 \\
\hline No & $2324(64.9)$ & 1.00 & 1.00 & 1.00 \\
\hline Yes & $1258(35.1)$ & 1.36 (1.17 to 1.59$)$ & 1.36 (1.16 to 1.59$)$ & 1.38 (1.17 to 1.62$)$ \\
\hline
\end{tabular}

Table 3

Association between insomnia and carotid plaque odds by cross-classification analysis

\begin{tabular}{|lllll|}
\hline Shift work & Insomnia & Sleep duration & $\mathbf{n}(\%)$ & OR (95\% Cl) \\
\hline Never/Ever & No & $\geq 6$ hours & $913(25.5)$ & 1.00 \\
\hline Never/Ever & No & $<6$ hours & $68(1.9)$ & $1.43(0.81$ to 2.53) \\
\hline Never/Ever & Yes & $\geq 6$ hours & $409(11.4)$ & $1.34(0.98$ to 1.82) \\
\hline Never/Ever & Yes & $<6$ hours & $74(2.1)$ & $1.70(0.98$ to 2.95) \\
\hline Current & No & $\geq 6$ hours & $1202(33.6)$ & $1.54(1.00$ to 2.04) \\
\hline Current & No & $<6$ hours & $141(3.9)$ & $1.09(0.71$ to 1.66) \\
\hline Current & Yes & $\geq 6$ hours & $614(17.1)$ & 2.34 (1.82 to 2.99) \\
\hline Current & Yes & $<6$ hours & 161 (4.5) & 1.59 (1.08 to 2.36) \\
\hline $\begin{array}{l}\text { Adjusted for age, sex, marital status, educational level, BMI (categorical), smoking, drinking, DASH } \\
\text { score, physical activity, shift work, sleep duration (categorical), sleep drug, snore, hypertension, } \\
\text { diabetes, dyslipidemia. BMI, body mass index; DASH, dietary approaches to stop hypertension. }\end{array}$ \\
\hline
\end{tabular}


Table 4

Associations between insomnia and carotid plaque stratified by sex, smoking status, drinking status, BMI, DASH score, hypertension, diabetes and dyslipidemia

\begin{tabular}{|c|c|c|c|}
\hline \multirow[t]{2}{*}{ Characteristics } & \multicolumn{2}{|l|}{ OR $(95 \% \mathrm{Cl})$} & \multirow[t]{2}{*}{$p_{\text {Interaction }}$} \\
\hline & Non-insomnia & Insomnia & \\
\hline \multicolumn{3}{|l|}{ Sex } & 0.353 \\
\hline Male & 1.00 & 1.37 (1.16 to 1.63$)$ & \\
\hline Female & 1.00 & 1.78 (0.84 to 3.76$)$ & \\
\hline \multicolumn{3}{|l|}{ Smoking status } & 0.776 \\
\hline Never/Ever & 1.00 & 1.44 (1.13 to 1.85$)$ & \\
\hline Current & 1.00 & 1.37 (1.10 to 1.71$)$ & \\
\hline \multicolumn{3}{|l|}{ Drinking status } & 0.054 \\
\hline Never/Ever & 1.00 & 1.65 (1.32 to 2.05$)$ & \\
\hline Current & 1.00 & 1.14 (0.88 to 1.47$)$ & \\
\hline \multicolumn{3}{|l|}{ BMI $\left(\mathrm{kg} / \mathrm{m}^{2}\right)$} & 0.392 \\
\hline$<25$ & 1.00 & 1.52 (1.20 to 1.93$)$ & \\
\hline$\geq 25$ & 1.00 & 1.31 (1.04 to 1.65$)$ & \\
\hline \multicolumn{3}{|l|}{ DASH score } & 0.456 \\
\hline$<21$ & 1.00 & 1.28 (1.01 to 1.62 ) & \\
\hline$\geq 22$ & 1.00 & 1.51 (1.20 to 1.91$)$ & \\
\hline \multicolumn{3}{|l|}{ Hypertension } & 0.412 \\
\hline No & 1.00 & 1.29 (1.05 to 1.60$)$ & \\
\hline Yes & 1.00 & 1.60 (1.22 to 2.10$)$ & \\
\hline \multicolumn{3}{|l|}{ Diabetes } & 0.261 \\
\hline No & 1.00 & 1.47 (1.22 to 1.76$)$ & \\
\hline Yes & 1.00 & 1.15 (0.76 to 1.72$)$ & \\
\hline \multicolumn{3}{|l|}{ Dyslipidemia } & 0.127 \\
\hline \multicolumn{4}{|c|}{$\begin{array}{l}p \text {-values for interaction were estimated using a log likelihood ratio test to compare models with anc } \\
\text { without cross-product interaction terms. } p \text { Interaction were derived by insomnia } \times \text { characteristics in } \\
\text { Models that adjusted for age, sex, marital status, educational level, BMI (categorical), smoking, } \\
\text { drinking, DASH score, physical activity, shift work, sleep duration (categorical), sleep drug, snore, } \\
\text { hypertension, diabetes, dyslipidemia (except for the stratification variable in each subgroup). BMI, } \\
\text { body mass index; DASH, dietary approaches to stop hypertension. }\end{array}$} \\
\hline
\end{tabular}




\begin{tabular}{|c|c|c|c|}
\hline \multirow[t]{2}{*}{ Characteristics } & \multicolumn{2}{|l|}{ OR $(95 \% \mathrm{Cl})$} & \multirow[t]{2}{*}{$p_{\text {Interaction }}$} \\
\hline & Non-insomnia & Insomnia & \\
\hline No & 1.00 & 1.63 (1.31 to 2.03 ) & \\
\hline Yes & 1.00 & 1.12 (0.87 to 1.45$)$ & \\
\hline \multicolumn{4}{|c|}{$\begin{array}{l}\text { p-values for interaction were estimated using a log likelihood ratio test to compare models with and } \\
\text { without cross-product interaction terms. } p \text { Interaction were derived by insomnia } \times \text { characteristics in } \\
\text { Models that adjusted for age, sex, marital status, educational level, BMI (categorical), smoking, } \\
\text { drinking, DASH score, physical activity, shift work, sleep duration (categorical), sleep drug, snore, } \\
\text { hypertension, diabetes, dyslipidemia (except for the stratification variable in each subgroup). BMI, } \\
\text { body mass index; DASH, dietary approaches to stop hypertension. }\end{array}$} \\
\hline
\end{tabular}

\section{Discussion}

In this cross-sectional study of occupational populations, we examined the association between insomnia and subclinical atherosclerosis. The prevalence of carotid plaque among insomnia workers and non-insomnia workers were $27.7 \%$ and $33.9 \%$, respectively. Positive associations were observed between insomnia and odds of carotid plaque after adjustment for possible confounding factors, adding evidence to an underlying pro-atherogenic role of insomnia in cardiovascular disease.

Previous study found that carotid intima media thickness (CIMT) was significantly greater in insomnia group and insomnia with short sleep duration was associated with high plaque score [22]. Another study among midlife women found that shorter objective sleep time and poorer subjective sleep quality were associated with higher mean IMT and higher odds of carotid plaque adjusting for CVD risk factors, hot flashes, and estradiol [32]. Carotid plaque is a more direct measure of atherosclerotic lesion development, and has been shown to improve significantly the better risk prediction of CVD risk factors than CIMT [3234]. However, our study showed an association between insomnia and carotid plaque among male workers but not among female workers, which was in consistent with another similar study [35]. Female workers have a lower percentage of shift work than the male workers in the steel industry, which could partly explain the sex discrepancies in the effect of insomnia on carotid plaque. Considering the small sample size of women in our study, the relationship between insomnia and atherosclerotic process in female deserves further study in a large sample. Our findings extend the positive association between insomnia and odds of carotid plaque for adding findings that when insomnia, the sleep duration and shift work are considered simultaneously, significantly higher odds of carotid plaque are limited to participants who have been exposed to shift work and insomnia. Whereas shift work cannot be completely avoided in industrial production. This implies that improving insomnia symptoms, or transferring workers with severe insomnia from shift work to day work, may reduce the odds of carotid plaque and protect workers' health. 
The exact mechanism by which sleep disorders may increase risk for atherosclerosis, stroke and vascular disease have not well been established. Several probable pathways are likely to underlie the association between insomnia and subclinical atherosclerosis. One potential mechanism is the presence of psychological and psychosocial stressors [36]. Shift workers are subject to heavier stress loads (such as job strain or community-wide events) [37], and suffer mental health problems (such as depression or fatigue) compared to non-shift workers [38]. One of the principal mechanisms translating chronic stress into adverse cardio-metabolic outcomes is up-regulation of the hypothalamic pituitary adrenal (HPA) axis [39]. In addition, the consequences of sleep deprivation to the sympathetic system and endocrine system have been demonstrated both in animals and insomnia subjects by increasing sympathetic activity, causing vascular endothelial dysfunction[40], elevating evening corticotropin and cortisol levels [41], reducing natural killer cell activity and increasing pro-inflammatory cytokines [42]. These could be the important underlying pathophysiological mechanisms of atherosclerosis. Furthermore, unhealthy behavioral lifestyle behaviors (e.g. less exercise, alcohol consumption) can increase the risk of insomnia [43]. Insomnia is also associated with higher nighttime systolic blood pressure, blunted dipping of nocturnal blood pressure [44], higher risks of developing hypertension [45], diabetes [46, 47] and dyslipidemia [48]. In our study, insomnia workers showed shorter sleep duration, less physical activity and higher levels of systolic blood pressure and diastolic blood pressure than non-insomnia workers. All these are correlated with increased risk of CVD and risk factors, have the potential to rupture vulnerable plaque and facilitate thrombus formation, resulting in myocardial infarction or sudden death [49].

The major strengths of our study include a large sample size and accurate calculation of carotid plaque by ultrasonography. However, our research also has certain limitations. First, we are unable to draw any causal inferences between insomnia and carotid plaque according to a cross-sectional study. Second, even though ASI is a widely used epidemiological tool to assess insomnia, it is not used for clinical diagnosis of insomnia. Third, we were not able to obtain objective measures of sleep by polysomnography, the use of self-reported snoring more than 4 times a week as a surrogate for sleep disordered breathing may dilute any effects on carotid plaque by including subjects with primary snoring (no apneas) or mild sleep disordered breathing. Fourth, our study did not collect information about physical pain and mental disorders, which may have an impact on insomnia, although we did take sleep drug and snore into account. Fifth, our survey participants are currently participating in the standard fourcrew-three-shift system, and other different shift systems were only found during the historical period, which made it impossible to compare between insomnia and different type of shift system. However, it can be postulated that shift workers experience insomnia at each sleeping period related to their work schedule [50]. Finally, this study was conducted in the occupational population of steel production, among which male workers account for the majority, which limits the results to general population.

\section{Conclusion}

In conclusion, insomnia is association with subclinical atherosclerosis in male steelworkers. Insomnia problems of workers should receive further attention in occupational worker health interventions. Further large-scale prospective longitudinal studies are warranted to confirm our findings. 


\section{Abbreviations}

AIS: Athens Insomnia Scale; DASH: dietary approaches to stop hypertension; MET: metabolic equivalent of task; BMI: body mass index; HDL-C: high density lipoprotein cholesterol; LDL-C: low density lipoprotein cholesterol; OR: odds ratio; Cl: confidence interval; CVD: cardiovascular diseases; SWD: shift work disorder.

\section{Declarations}

\section{Ethics approval and consent to participate}

All participants gave informed consent before taking part in this study. The research was approved by the Ethics Committee of North China University of Science and Technology (No.16040).

\section{Consent for publication}

Not application.

\section{Availability of data and materials}

The datasets generated and analyzed in the course of this study are available from the corresponding author on reasonable request.

\section{Competing interests}

None declared.

\section{Funding}

This work was supported by the National Key R\&D Program of China (No. 2016YFC0900605) and the Graduate Student Innovation Fund of North China University of Science and Technology (No. CXZZBS2019136).

\section{Authors' contributions}

WLH raised the study concept and drafted the manuscript. ZSK conceived and designed this work. YM analysed the data and provided inputs and revisions. YJX supervised the fieldwork of this project. 


\section{Acknowledgements}

The authors are grateful to all the participants of this study and all members involving the collection of the baseline data.

\section{References}

1. Buysse DJ: Insomnia. JAMA 2013, 309(7):706-716.

2. Ohayon MM: Epidemiology of insomnia: what we know and what we still need to learn. Sleep medicine reviews 2002, 6(2):97-111.

3. Li X, Cui S, Wu J, Wang L, Yuan J: Job category differences in the prevalence and associated factors of insomnia in steel workers in China. International journal of occupational medicine and environmental health 2020, 33(2):215-233.

4. Han X, Yang Y, Chen Y, Gao L, Yin X, Li H et al: Association between insomnia and atrial fibrillation in a Chinese population: A cross-sectional study. Clinical cardiology 2017, 40(9):765-769.

5. Kessler RC, Berglund PA, Coulouvrat C, Hajak G, Roth T, Shahly V et al: Insomnia and the performance of US workers: results from the America insomnia survey. Sleep 2011, 34(9):1161-1171.

6. Sarsour K, Kalsekar A, Swindle R, Foley K, Walsh JK: The association between insomnia severity and healthcare and productivity costs in a health plan sample. Sleep 2011, 34(4):443-450.

7. Ford ES, Cunningham TJ, Giles WH, Croft JB: Trends in insomnia and excessive daytime sleepiness among U.S. adults from 2002 to 2012. Sleep medicine 2015, 16(3):372-378.

8. Lancet GCoDCJ: Global, regional, and national age-sex specific mortality for 264 causes of death, 1980-2016: a systematic analysis for the Global Burden of Disease Study 2016. 2017, 390(10100):1151-1210.

9. Zhao D, Liu J, Wang M, Zhang X, Cardiology MZJNr: Epidemiology of cardiovascular disease in China: current features and implications. 2019, 16(4):203-212.

10. Jankowiak S, Backé E, Liebers F, Schulz A, Hegewald J, Garthus-Niegel S et al: Current and cumulative night shift work and subclinical atherosclerosis: results of the Gutenberg Health Study. 2016, 89(8):1169-1182.

11. Laclaustra M, Casasnovas JA, Fernández-Ortiz A, Fuster V, León-Latre M, Jiménez-Borreguero LJ et al: Femoral and Carotid Subclinical Atherosclerosis Association With Risk Factors and Coronary Calcium: The AWHS Study. 2016, 67(11):1263-1274.

12. Atherosclerosis JDSJ: Carotid plaque measurement is superior to IMT Invited editorial comment on: carotid plaque, compared with carotid intima-media thickness, more accurately predicts coronary artery disease events: a meta-analysis-Yoichi Inaba, M.D., Jennifer A. Chen M.D., Steven R. Bergmann M.D., Ph.D. 2012, 220(1):34-35. 
13. Sillesen H, Sartori S, Sandholt B, Baber U, Mehran R, Imaging VFJEhjc: Carotid plaque thickness and carotid plaque burden predict future cardiovascular events in asymptomatic adult Americans. 2018, 19(9):1042-1050.

14. Hirata T, Arai Y, Takayama M, Abe Y, Ohkuma K, atherosclerosis TTJJo et al: Carotid Plaque Score and Risk of Cardiovascular Mortality in the Oldest Old: Results from the TOOTH Study. 2018, 25(1):55-64.

15. Gepner AD, Young R, Delaney JA, Budoff MJ, Polak JF, Blaha MJ et al: Comparison of Carotid Plaque Score and Coronary Artery Calcium Score for Predicting Cardiovascular Disease Events: The MultiEthnic Study of Atherosclerosis. 2017, 6(2).

16. Polak JF, Szklo M, Kronmal RA, Burke GL, Shea S, Zavodni AEH et al: The value of carotid artery plaque and intima-media thickness for incident cardiovascular disease: the multi-ethnic study of atherosclerosis. 2013, 2(2):e000087.

17. Booker LA, Magee M, Rajaratnam SMW, Sletten TL, Howard ME: Individual vulnerability to insomnia, excessive sleepiness and shift work disorder amongst healthcare shift workers. A systematic review. Sleep medicine reviews 2018, 41:220-233.

18. Milia LD, Waage S, Pallesen S, Bjorvatn B: Shift work disorder in a random population sampleprevalence and comorbidities. PloS one 2013, 8(1):e55306.

19. Drake CL, Roehrs T, Richardson G, Walsh JK, Roth T: Shift work sleep disorder: prevalence and consequences beyond that of symptomatic day workers. Sleep 2004, 27(8):1453-1462.

20. Flo E, Pallesen S, Magerøy N, Moen BE, Grønli J, Nordhus IH et al: Shift work disorder in nursesassessment, prevalence and related health problems. PloS one 2012, 7(4):e33981.

21. Wickwire EM, Geiger-Brown J, Scharf SM, Drake CL: Shift Work and Shift Work Sleep Disorder: Clinical and Organizational Perspectives. Chest 2017, 151(5):1156-1172.

22. Nakazaki C, Noda A, Koike Y, Yamada S, Murohara T, Ozaki N: Association of insomnia and short sleep duration with atherosclerosis risk in the elderly. American journal of hypertension 2012, 25(11):1149-1155.

23. McAlpine CS, research FKSJC: Circadian Influence on Metabolism and Inflammation in Atherosclerosis. 2016, 119(1):131-141.

24. Ramos-Sepulveda A, Wohlgemuth W, Gardener H, Lorenzo D, Dib S, Wallace DM et al: Snoring and insomnia are not associated with subclinical atherosclerosis in the Northern Manhattan Study. International journal of stroke: official journal of the International Stroke Society 2010, 5(4):264-268.

25. Soldatos CR, Dikeos DG, Paparrigopoulos TJ: Athens Insomnia Scale: validation of an instrument based on ICD-10 criteria. Journal of psychosomatic research 2000, 48(6):555-560.

26. Touboul P-J, Hennerici MG, Meairs S, Adams H, Amarenco P, Bornstein N et al: Mannheim carotid intima-media thickness and plaque consensus (2004-2006-2011). An update on behalf of the advisory board of the 3rd, 4th and 5th watching the risk symposia, at the 13th, 15th and 20th European Stroke Conferences, Mannheim, Germany, 2004, Brussels, Belgium, 2006, and Hamburg, Germany, 2011. 2012, 34(4):290-296. 
27. Puttonen S, Kivimäki M, Elovainio M, Pulkki-Råback L, Hintsanen $M$, Vahtera J et al: Shift work in young adults and carotid artery intima-media thickness: The Cardiovascular Risk in Young Finns study. 2009, 205(2):608-613.

28. Crouse JR, Harpold GH, Kahl FR, Toole JF, Stroke WMMJ: Evaluation of a scoring system for extracranial carotid atherosclerosis extent with B-mode ultrasound. 1986, 17(2):270-275.

29. Maskarinec G, Lim U, Jacobs S, Monroe KR, Ernst T, Buchthal SD et al: Diet Quality in Midadulthood Predicts Visceral Adiposity and Liver Fatness in Older Ages: The Multiethnic Cohort Study. Obesity (Silver Spring, Md) 2017, 25(8):1442-1450.

30. Celis-Morales CA, Perez-Bravo F, Ibañez L, Salas C, Bailey MES, Gill JMR: Objective vs. self-reported physical activity and sedentary time: effects of measurement method on relationships with risk biomarkers. PloS one 2012, 7(5):e36345.

31. Zhang S, Wang Y, Wang Z, Wang H, Xue C, Li Q et al: Rotating night shift work and non-alcoholic fatty liver disease among steelworkers in China: a cross-sectional survey. 2020, 77(5):333-339.

32. Thurston RC, Chang Y, Känel Rv, Barinas-Mitchell E, Jennings JR, Hall MH et al: Sleep Characteristics and Carotid Atherosclerosis Among Midlife Women. Sleep 2017, 40(2).

33. Laclaustra M, Casasnovas JA, Fernández-Ortiz A, Fuster V, León-Latre $M$, Jiménez-Borreguero LJ et al: Femoral and Carotid Subclinical Atherosclerosis Association With Risk Factors and Coronary Calcium: The AWHS Study. Journal of the American College of Cardiology 2016, 67(11):1263-1274.

34. Fernández-Friera L, Peñalvo JL, Fernández-Ortiz A, Ibañez B, López-Melgar B, Laclaustra $M$ et al: Prevalence, Vascular Distribution, and Multiterritorial Extent of Subclinical Atherosclerosis in a Middle-Aged Cohort: The PESA (Progression of Early Subclinical Atherosclerosis) Study. Circulation 2015, 131(24):2104-2113.

35. Mallon L, Broman JE, Hetta J: Sleep complaints predict coronary artery disease mortality in males: a 12-year follow-up study of a middle-aged Swedish population. Journal of internal medicine 2002, 251(3):207-216.

36. Thomas C, Power C: Shift work and risk factors for cardiovascular disease: a study at age $\mathbf{4 5}$ years in the 1958 British birth cohort. European journal of epidemiology 2010, 25(5):305-314.

37. Roskoden FC, Krüger J, Vogt LJ, Gärtner S, Hannich HJ, Steveling A et al: Physical Activity, Energy Expenditure, Nutritional Habits, Quality of Sleep and Stress Levels in Shift-Working Health Care Personnel. PloS one 2017, 12(1):e0169983.

38. Bazazan A, Rasoulzadeh Y, Dianat I, Safaiyan A, Mombeini Z: Occupational fatigue and mental health complaints among 8-hour shift workers of petrochemical industries in Iran. Work (Reading, Mass) 2019, 62(2):309-317.

39. Lechner K, Schacky Cv, McKenzie AL, Worm N, Nixdorff U, Lechner B et al: Lifestyle factors and highrisk atherosclerosis: Pathways and mechanisms beyond traditional risk factors. European journal of preventive cardiology 2020, 27(4):394-406.

40. Carreras A, Zhang SX, Peris E, Qiao Z, Gileles-Hillel A, Li RC et al: Chronic sleep fragmentation induces endothelial dysfunction and structural vascular changes in mice. Sleep 2014, 37(11):1817- 
1824.

41. Vgontzas AN, Bixler EO, Lin HM, Prolo P, Mastorakos G, Vela-Bueno A et al: Chronic insomnia is associated with nyctohemeral activation of the hypothalamic-pituitary-adrenal axis: clinical implications. The Journal of clinical endocrinology and metabolism 2001, 86(8):3787-3794.

42. Irwin MR: Why sleep is important for health: a psychoneuroimmunology perspective. Annual review of psychology 2015, 66:143-172.

43. Chen L-J, Steptoe A, Chen Y-H, Ku P-W, Lin C-H: Physical activity, smoking, and the incidence of clinically diagnosed insomnia. Sleep medicine 2017, 30:189-194.

44. Lanfranchi PA, Pennestri M-H, Fradette L, Dumont M, Morin CM, Montplaisir J: Nighttime blood pressure in normotensive subjects with chronic insomnia: implications for cardiovascular risk. Sleep 2009, 32(6):760-766.

45. Vgontzas AN, Liao D, Bixler EO, Chrousos GP, Vela-Bueno A: Insomnia with objective short sleep duration is associated with a high risk for hypertension. Sleep 2009, 32(4):491-497.

46. Cappuccio FP, D'Elia L, Strazzullo P, Miller MA: Quantity and quality of sleep and incidence of type 2 diabetes: a systematic review and meta-analysis. Diabetes care 2010, 33(2):414-420.

47. Knutson KL, Cauter EV, Zee P, Liu K, Lauderdale DS: Cross-sectional associations between measures of sleep and markers of glucose metabolism among subjects with and without diabetes: the Coronary Artery Risk Development in Young Adults (CARDIA) Sleep Study. Diabetes care 2011, 34(5):1171-1176.

48. Clark AJ, Salo P, Lange T, Jennum P, Virtanen M, Pentti J et al: Onset of Impaired Sleep and Cardiovascular Disease Risk Factors: A Longitudinal Study. Sleep 2016, 39(9):1709-1718.

49. Schwartz BG, French WJ, Mayeda GS, Burstein S, Economides C, Bhandari AK et al: Emotional stressors trigger cardiovascular events. International journal of clinical practice 2012, 66(7):631639.

50. Vallières A, Azaiez A, Moreau V, LeBlanc M, Morin CM: Insomnia in shift work. Sleep medicine 2014, 15(12):1440-1448.

\section{Supplementary Files}

This is a list of supplementary files associated with this preprint. Click to download.

- Supplementary.docx 